\title{
Sexism at the Bar and the Equitable Briefing Policy: A Well-Meaning but Misguided Response to Gendered Briefing Practices
}

\author{
RYAN CHAN*
}

\begin{abstract}
This article considers a recent regulatory initiative formulated by the Law Council of Australia called the Equitable Briefing Policy ('EBP'), which aims to address the disadvantage experienced by female practitioners at the Australian Bar. This article examines the origins and underlying rationales of the Policy. It contends that the Policy's potential in deinstitutionalising gendered briefing practices at the Australian Bar is inhibited by Australia's policymaking avoidance towards any form of 'affirmative action'. This aversion is due to the conventional understanding that affirmative action and the merit principle are positioned in a dichotomous relationship, and thus remain inherently in tension with one another. It is argued, however, that in the context of briefing practices in Australia, such an understanding is primitive, and using merit as a means of rejecting other policy approaches only serves to inhibit the Policy's application and effect.
\end{abstract}

\section{Introduction}

In many Western countries today, women are graduating from law school in a higher proportion than men. ${ }^{1}$ However, the large disparity between men and women in rates of retention and seniority continues to endure within most branches of the legal profession. Studies conducted in Australia, the United States of America, Canada, Wales, and England have all documented significant under-representation of women in senior legal

* BEcon/LLB candidate at the University of Queensland. The author would like to thank Dr Francesca Bartlett, Senior Lecturer at the TC Beirne School of Law, for her insightful comments and guidance over this article.

1 In 2012, it was reported that 63 percent of law graduates in Australia were women, and tended to outperform male students academically: Graduate Careers Australia, Australian Graduate Survey (2012). See also Felicity Nelson, 'Law Graduate Unemployment Hits Record High', Lawyers Weekly, 9 January 2015; Sarah Martin, 'Gender Gap Widens', The Australian, 17 August 2015; 'Encouraging Gender Diversity in the Legal Profession', The College of Law, 13 March 2014; New South Wales Equitable Briefing Working Group, Review of the Application in New South Wales of the Equitable Briefing Policy of the Law Council of Australia (Report to the President of the New South Wales Bar Association, August 2015) $<$ https://www.nswbar.asn.au/docs/webdocs/eb_report_01092015.pdf>. 
positions, and higher rates of women than men either leaving legal practice within their junior years or not going on to practise law at all. ${ }^{2}$

Such gender inequalities are particularly prevalent at the Australian Bar, as reported by numerous empirical studies over the past two decades. ${ }^{3}$ This is seen in quantitative terms, such as significantly lower earnings, fewer senior and junior female barristers compared to male barristers, and fewer appearances in superior courts. ${ }^{4}$ It is also seen in qualitative terms, such as lingering gendered roles requiring women to cope with competing work and family responsibilities, gendered assumptions about aptitudes to perform the advocacy role, and homosocial behaviour at the Bar. ${ }^{5}$ The details of these findings will be further discussed in Part II of this article.

Over the past two decades, the Law Council of Australia has attempted to respond to these gendered disadvantages by way of regulatory briefing initiatives. These initiatives are the Equitable Briefing Policy ('EBP'), and its predecessor, the Model Equal Opportunity Briefing Policy ('MBP'). This article contends that despite several amendments, the EBP retains many of the flaws of its predecessor. The EBP lacks clarity in application, is built upon targetless objectives, and, of more concern, proceeds on illinformed understandings of merit-based selection and affirmative action. While this may be the result of inevitable compromises in the process of developing an uncontroversial national policy, it is argued that it can also be attributed to a strong aversion to developing any regulatory initiative which could be characterised as a form of affirmative action. ${ }^{6}$

Parts III and IV outline the major criticisms of the EBP, and examine the two concepts of merit and affirmative action in the context of the briefing practices. Part IV argues that to constrain the EBP to the oppositional relationship between merit and affirmative action is flawed, and that to do so only inhibits the effectiveness of the Policy itself. Part V

2 The entry and progression of women have been widely documented in the United Kingdom and Canada: see, eg, Hilary Sommerlad and Peter Sanderson, Gender Choice and Commitment: Women Solicitors in England and Wales and the Struggle for Equal Status (Ashgate/Dartmouth, 1998); Joan Brockman, Gender in the Legal Profession: Fitting or Breaking the Mould (UBC Press, 2001); Jean McKenzie Leiper, Bar Codes: Women in the Legal Profession(UBC Press, 2007). Studies have revealed similar trends in the United States: see, eg, Paula A Patton, 'Women Lawyers, Their Status, Influence and Retention in the Legal Profession' (2005) 11 William and Mary Journal of Women and the LaW 173; American Bar Association, A Current Glance at Women in the Law (2016).

3 See, eg, Rosemary Hunter and Helen McKelvie, Victorian Bar Council, Equality of Opportunity for Women at the Victorian Bar - A Report to the Victorian Bar Council(1998); Australian Women Lawyers, Gender Appearance Survey Information (2006); Law Council of Australia, Court Appearance Survey: Beyond the Statistical Gap (2009); Law Council of Australia, National Attrition and Re-Engagement Study Report (2014) ('NARS Report').

4 See, eg, Hunter and McKelvie, above n 3, xi; Australian Women Lawyers, above n 3, 17-44; Law Council of Australia, Court Appearance Survey: Beyond the Statistical Gap, above n 3, $1-16$.

5 See, eg, Hunter and McKelvie, above n 3, 31; Law Council of Australia, NARS Report, above n 3, 35-76.

6 Francesca Bartlett, 'Model Advocates or a Model for Change?' (2008) 32 Melbourne University Law Review 351, 353. 
proposes a range of 'harder', more proactive measures which should be a part of the EBP in order to remedy its current ineffectiveness.

It is important to note from the outset that this article will not delve into the Australian Solicitors' Conduct Rules, ${ }^{7}$ legislation, ${ }^{8}$ and case law ${ }^{9}$ pertinent to gender inequality. While such legal and ethical forms of redress exist within the sphere of gender inequality in the legal profession, they fall outside the scope of this article. Furthermore, this article does not seek to argue that gendered briefing practices is the sole reason for the difficulties junior and senior female barristers experience at the Bar. It is acknowledged that there are other factors, not necessarily pertaining to gender, which may affect the success of barristers generally. ${ }^{10}$

\section{Gender Inequality at the Bar}

As expressed above, gender inequality within the legal profession continues to be the subject of much academic discussion and empirical analysis across the Western world. ${ }^{11}$ Coupled with this is the contention of the 'trickle-up' approach, ${ }^{12}$ which posits that the historical predominance of men in the field of law will simply resolve itself over time. ${ }^{13}$ However, in light of recent empirical studies, there is strong evidence that this view is incorrect, particularly with regard to the Australian Bar. While formal barriers to entry no longer exist, ${ }^{14}$ women still find themselves informally

Specifically the Law Council of Australia, Australian Solicitors Conduct Rules (2015) r 42.

8 See, eg, Sex Discrimination Act 1984 (Cth); Fair Work Act 2009 (Cth); Equal Opportunity Act 2010 (Vic).

9 See, eg, Hickie $v$ Hunt and Hunt (1998) HREOCA 8. Ms Hickie alleged that the law firm Hunt and Hunt discriminated against her on the ground of sex. The Australian Human Rights and Equal Opportunity Commission found that there had been 'indirect sex discrimination' under s 5(2) of the Sex Discrimination Act 1984 (Cth), and awarded compensation of $\$ 95,000$. See also Fraser-Kirk v David Jones Limited(2010) FCA 1060 (29 September, 2010).

10 For example, the substantial growth in alternative dispute resolution in preference to litigation over recent years will continue to be a challenge for barristers of all levels of seniority. A relevant but distinct challenge is the increase in the number of solicitor advocates and in-house counsel, resulting in a decrease of work previously handled by junior members of the Bar. See, eg, Sebastian Chia, 'Alternative Dispute Resolution Services in Australia' (Industry Report, IBISWorld, February 2015); Melissa Hanks, 'Perspectives on Mandatory Mediation', (2012) 35 University of New South Wales 929; Paul Covers, 'Alternative or Mainstream? Is it Time to Take the 'A' Out of ADR' (Gazette, Proctor, October 2015).

11 See, eg, Margaret Thornton, Dissonance and Distrust: Women in the Legal Profession(Oxford University Press, 1996); Cynthia Fuchs Epstein, Women in Law (Basic Books, 1981); Nancy J Reichman and Joyce S Sterling, 'Sticky Floors, Broken Steps, and Concrete Ceilings in Legal Careers' (2004) 14 Texas Journal of Women and the Law 27.

12 The 'trickle-up' approach is based on the expectation that the changing composition of the legal profession will naturally and automatically result in much great numbers of women and minority lawyers being appointed to the bench: Kate Malleson, 'Rethinking the Merit Principle in Judicial Selection' (2006) 33 Journal of Law and Society 126. See also Commission for Judicial Appointments, Annual Report (2003) 4.

13 Bartlett, above n 6, 354.

14 At the turn of the twentieth century women were 'let into' the legal profession in the common law world. However, it was not until the 1970s that women entered the Australian legal profession in substantial numbers: Law Council of Australia, Court Appearance Survey, 
excluded from entering or progressing in the profession by way of gendered briefing practices and sexist Bar culture. As observed by Former High Court Justice, Mary Gaudron, 'the trouble with women of my generation is that we thought if we knocked the doors down, success would be inevitable.' 15 Chief Justice of the Victorian Supreme Court, Marilyn Warren, commented that, 'there is impatience that change is not occurring more rapidly' and 'there is irritation at ongoing discrimination against women.' 16 These sentiments were echoed in 2015, where the Federal Court Chief Justice, James Allsop, stated that the Courts have a responsibility to make it clear the 'male-club-like-blokiness in the conduct of litigation' is unacceptable. ${ }^{17}$

In Australia, four large empirical studies spanning from 1998 to 2014 have been conducted in relation to the working lives of women at the Bar. These studies not only provide significant evidence that female practitioners are being discriminated against at an institutional level, but also that the official efforts over the past 15 years in combatting these disadvantages have seen very little success.

\section{A The Hunter and McKelvie Report}

The first study, commissioned by the Victorian Bar Council, was undertaken by Rosemary Hunter and Helen McKelvie in 1997-98. They conducted a wide-ranging review of the culture of the Victorian Bar by recording court appearances and interviewing judges, barristers, clerks, and briefing solicitors. ${ }^{18}$ With regard to quantitative analysis, the empirical evidence showed significantly lower levels of seniority, rates of advancement and court appearances for female barristers when compared to their male counterparts. Qualitative analysis and recommendations for change within the Bar were also provided. Of particular importance was the conclusion that the 'greatest barrier to change [for women] is the culture of the bar itself.' ${ }^{19}$ Here, they described the culture as characteristic of 'hegemonic masculinity'. ${ }^{20}$ These included a prevailing prejudice that the

above $\mathrm{n} 3,10$. For a thorough discussion of the exclusion of women in the history of the Australian legal profession, see Thornton, above $\mathrm{n} 11$.

15 Justice Mary Gaudron, 'Speech to Launch Australia Women Lawyers' (Speech delivered at the Australian Women Lawyers Launch, Melbourne, 19 September 1997).

16 Justice Marilyn Warren, 'Promoting Difference' (Speech delivered at the Victorian Women Lawyer Achievement Awards, Melbourne, 15 May 2003).

17 Chief Justice James Allsop, 'Remarks Made by Chief Justice Allsop' (Speech delivered at the Launch of the Commercial Bar Association of Victoria Equitable Briefing Initiative, Melbourne, 11 November 2015).

18 Hunter and McKelvie, above n 3. This project consisted of a literature review, 125 interviews with legal personnel, two focus groups with members of list committees and a study of court and tribunal appearances over a three-month period.

19 Rosemary Hunter, 'Women Barristers and Gender Difference' in Ulrike Shultz and Gisela Shaw (eds), Women in the World's Legal Professions (Hart Publishing, 2003) 103, 104.

20 This is in particular reference to the overlap of constructions of masculinity and of law as rational, authoritative, and objective. It has hence been constructed that men are better suited 
model advocate requires masculine qualities, making women inherently inferior in performing the advocacy role; and the presumption that women are unable to show complete commitment to the profession due to competing narratives of being the ideal lawyer and the ideal mother. ${ }^{21}$ It was also noted that the collegiate nature of the Bar, also colloquially known as a 'boys club', often formed internal barriers that disadvantaged and excluded women from the profession. 22

Such prejudicial ideas were also exhibited by their solicitor counterparts by way of gendered briefing practices. ${ }^{23}$ This is particularly detrimental to female practitioners, as success at the Bar is highly predicated on the steady inflow of complex briefs. Briefs not only sustain their wage and their practice, but also act as a means of developing reputation and ensuring progression within the profession. ${ }^{24}$

Hunter and McKelvie found that women barristers were being 'pigeonholed' into certain areas of law due to stereotypical assumptions about their abilities and interests. It was reported that they were significantly 'overrepresented in family law, and significantly under-represented in commercial law, common law and personal injury. ${ }^{25}$ This finding is not novel, and is a trend which has been widely reported around the world. Margaret Thornton commentated that due to enduring stereotypes of women, the result was the relegation of women into 'feminine areas' of law, ${ }^{26}$ leaving them significantly over-represented in the least prestigious and least remunerated areas of practice, and significantly underrepresented among the most elite positions. ${ }^{27}$ Deborah Rhode echoed these conclusions in respect to the profession in the United States. ${ }^{28}$

The predominance of selection by fraternal networks between the Bar and solicitor briefers was also seen as a major characteristic of gendered briefing practices. Female barristers faced significant difficulty in establishing themselves within the profession because senior male barristers were often inclined to recommend a junior from the 'boys club' ${ }^{29}$ Moreover, in instances where junior women managed to secure briefs with

to law, allowing for the notion of 'hegemonic masculinity' to carry throughout the Bar. For a discussion of this, see Thornton, above n 11; Ibid 106.

21 See, eg, Deborah Rhode, 'Gender and the Profession: An American Perspective' in Ulrike Schultz and Gisela Shaw (eds), Women in the World's Legal Professions (Hart Publishing, 2003), 3, 13-15; Sommerlad and Sanderson, above n 2; Hilary Sommerlad, 'Women Solicitors in a Fractured Profession: Intersections of Gender and Professionalism in England and Wales' (2002) 9 International Journal of the Legal Profession 213.

22 See Sharon Bolton and Daniel Muzio, 'Can't Live with 'Em; Can't Live without 'Em: Gendered Segmentation in the Legal Profession' (2007) 41 Sociology 47; Celia Davies, 'The Sociology of Professions and the Profession of Gender' (1996) 30 Sociology 661.

23 Hunter and McKelvie, above $\mathrm{n} 3$.

24 See also Bartlett, above n 6, 358

25 Hunter, above n 19, 4. See also Hunter and McKelvie, above n 3, 93.

26 Thornton, above $\mathrm{n} 11$.

27 Ibid 191.

28 Deborah Rhode, 'Gender and Professional Roles' (1994) 63 Fordham Law Review 39, 59. See also Epstein, above n 11; Patton, above n 2.

29 Hunter and McKelvie, above n 3, 68-9. 
senior counsel, they were 'faced with denigrating comments from male colleagues' who either impliedly or directly assert that they received such work purely 'on the basis of their looks or in return for sexual favours, rather than on merit.' 30 The interviews conducted with briefing solicitors also revealed similar inclinations to brief counsel according to fraternal networks; with personal rapport between barristers and solicitors and 'word of mouth' being the most significant influences in obtaining briefs. ${ }^{31}$ Although these are ostensibly gender-neutral factors, women are likely to be at a significant disadvantage due to the well-established, predominantly male network between briefing solicitors and the Bar. ${ }^{32}$

Ultimately, the Hunter and McKelvie report provided substantial evidence that female barristers at all levels of seniority are affected by these discriminatory cultures and practices, contesting the notion that the inequality of opportunities or predominance of men at the Bar will be remedied by a 'trickle up' of women over time. 33

\section{B Studies from the Australian Women Lawyers and Law Council of Australia}

Almost a decade after the Hunter and McKelvie report, Australian Women Lawyers conducted a second study of similar nature, which was called the Gender Appearance Survey Information: August 2006 ('Gender Appearance Survey'). ${ }^{34}$ The purpose of this study was to examine the appearance rates of female advocates in Australian State and Territory Supreme Courts and Federal Court. ${ }^{35}$ Here, they found a significant difference in the number, nature, and complexity of cases in which female advocates appeared compared to their male counterparts, further affirming the existence of gendered briefing practices across the Australian legal profession. Female barristers were significantly under-represented in every jurisdiction, received fewer complex, important or long running briefs compared to men, and paid proportionally less. ${ }^{36}$ Unsurprisingly, it was

30 Rosemary Hunter, 'Discrimination against Women Barristers: Evidence from a Study of Court Appearances and Briefing Practices' (2005) 12 International Journal of the Legal Profession $3,11-12$.

31 Ibid; Hunter and McKelvie, above n 3, 67-8.

32 Bartlett, above n 6, 359.

33 Hunter and McKelvie, above n 3.

34 Australian Women Lawyers, above n 3. The data was collected from surveys completed by court staff, which were completed in courts from all state, territory and federal courts with the exception of the Victorian courts and the Family Court of Australia. These surveys requested that the sex and seniority of the barrister appearing be recorded in each matter as well as the type and duration of the matter.

35 Ibid. Victoria was not included in the study as research was then being conducted into gender appearances in that State by the Victorian Bar's Equality before the Law Committee and the Victorian Bar Council. The Family Court did not participate in this study as anecdotal reports from judges and legal practitioners indicated a significant degree of representation of female advocates in that court.

36 A more in-depth analysis regarding significant disparities is provided by Kirton: Caroline Kirton, Explanatory Memorandum to Gender Appearance Survey Information August 2006 (2006). 
also documented that women were not being briefed in particular areas of law, receiving fewer briefs in civil or commercial areas compared to men; where they did receive briefs in these areas, they were often of minor nature or in a lower court. The Honourable Michael Kirby, in 2006, expressed a similar sentiment, in which he observed 'few female advocates with "speaking parts" during his more than 10 years on the High Court of Australia. 37

In 2007, the Law Council's Equalising Opportunities in the Law Committee proposed that a further survey be conducted to examine gender appearance rates in Australian superior courts. This proposal was approved by the Law Council Directors in 2008, and in 2009, an independent consultancy firm conducted the 2009 Court Appearance Survey: Beyond the Statistical Gap ('2009 Court Appearance Survey'). ${ }^{38}$ The key findings were: significant under-representation of female barristers, comprising only 19 percent of the Bar population in Australia at the time; the average appearance time for male barristers was significantly longer than female barristers, appearing for 3.8 hours and 2.8 hours respectively; in the Federal Court, only 5.8 percent of appearances by Senior Counsel were women; and the average length of hearing for male Senior and Junior Counsel was 223.6 hours compared to 1.4 hours for females in the same role. Due to the differing methodologies, the findings of the Gender Appearance Survey are not directly comparable to those found in the 2009 Court Appearance Survey. However, what can be concluded is that the appearance of female advocates before Australian courts remains significantly disproportionate compared to their male counterparts, and that women are being briefed in generally lower court matters at the expense of more complex, long running briefs.

In 2014, the Law Council of Australia released the National Attrition and Re-Engagement Study Report ('NARS Report'), ${ }^{39}$ which primarily reported upon the experiences, motivators, and drivers of attrition of women in all branches of the legal profession (and how they differed compared to men). Here, female barristers reported experiencing almost every form of discrimination or type of harassment at work compared to their fellow women in private practice or in-house legal roles. ${ }^{40}$ Female barristers are twice as likely as those in private practice or in-house roles

37 The Honourable Michael Kirby, 'Appellate Advocacy — New Challenges' (Speech delivered at the Dame Ann Ebsworth Memorial Lecture, London, 21 February 2006) 41.

38 The data was collected by the respective courts' associates as it was believed that, because of their unique roles, they were best placed to gather the required information. A survey was sent out to all respective courts across Australia.

39 Research was conducted over a 10-month period, and involved both qualitative and quantitative components. It included: an online survey of practising lawyers (3801 participants); online survey of lawyers who have left the profession (84 participants); online survey of individuals who have completed a law qualification but have no practised law (75 participants); 82 in-depth interviews with practising lawyers, lawyers no longer practising, individuals who have never practised, industry body representatives and HR managers.

40 For examples of the types of discrimination experienced, see Law Council of Australia, NARS Report, above n 3, 32 . 
to experience sexual harassment at their workplace, and also more likely than other females in the legal profession to experience discrimination due to gender, family or carer responsibilities, and bullying or intimidation. Female practitioners in this study also referred to both conscious and unconscious bias 41 at the Bar in relation to briefing practices. ${ }^{42}$ Furthermore, the NARS Report observed a significant pay disparity in the average gross annual fees of barristers, indicating that women are not receiving access to the number or the kind of briefs compared to their male counterparts. ${ }^{43}$

The issue of culture was also raised by participants of the study, and unsurprisingly, described as a significant aspect of job dissatisfaction or a barrier to career progression. Specifically, the culture was described as male dominated, 'blokey' and a 'boys club'. ${ }^{44}$ An anonymous former female barrister observed: 'It's a bit of a boys' club. There's still a lot of, it's not what you know it's who you know... Certainly, unfortunately, it still is very much a male dominated industry. Maybe not so much in the lower levels but certainly in the higher levels it is still very male oriented.' 45 In specific reference to briefing solicitors, female practitioners reported being denied work or opportunities purely on the basis of gender. ${ }^{46}$ One interviewee in her mid-30s wrote: 'I've been told on two occasions explicitly in the last 18 months that I didn't get the brief because I'm a woman, in writing...in the email they asked me too if I could recommend a male of my equivalent experience.' ${ }^{47}$ Another stated that 'it's very hard for women at the bar to get briefed because of unconscious bias by a lot of solicitors who are briefing them.' 48

Interviewees provided mixed reports regarding client prejudice on the basis of gender. Some stated that they had encountered several clients who explicitly expressed a preference for a male barrister, whereas other interviewees believed clients were more concerned about the 'ability to take instructions, give advice, and develop a trusting relationship' rather

41 See Law Council of Australia, 'Unconscious Bias Training Now Available to all Australian Lawyers' (Media Release, 8 March 2017). Law Council of Australia President, Fiona McLeod $\mathrm{SC}$, on addressing unconscious bias, 'Human beings are hardwired to notice personal characteristics and to prefer those with attributes or experiences similar to their own, without conscious awareness. Unconscious bias is an insidious and increasingly-recognised factor undermining organisational culture, leading to loss of productivity and revenue'. See also Law Council of Australia, NARS Report, above n 3, 80: Conscious bias includes female barristers being denied briefs because clients preferred male counsel. Unconscious bias includes courts and tribunals extending hearings well into the evenings without consulting counsel who have family commitments after-hours.

42 Law Council of Australia, NARS Report, above n 3, 6, 94

43 Ibid 93. This is an unsurprising observation, given that there are fewer women senior barristers at the Australian Bar. The dearth of women advocates is explored later in this article.

$44 \quad$ Ibid 39.

45 Ibid.

46 Ibid 35 .

47 Ibid.

48 Ibid. 
than the issue of gender. ${ }^{49}$ Nevertheless, client prejudice towards gender appears to play a role in briefing practices; the extent of its occurrence and effect, however, is unknown.

The sexual harassment of women at the Bar also appears to be prevalent, with many female practitioners reporting unwanted advances by their male counterparts or persistent exposure to inappropriate sexual behaviour. ${ }^{50}$ Moreover, they often feel excluded from conversations and social activities, and have difficulty identifying with the mainstream masculine culture. Many participants also feel that their career progression, reputation, and exposure to interesting work is negatively impacted by family responsibilities and related flexible working arrangements..$^{51}$

The NARS Report also asserts, by way of anecdotal evidence, that the current initiatives formed by the Law Council of Australia and respective law societies and Bar associations have been inadequate in combatting gendered briefing practices:

Several participants commented that there is a growing, if not sufficient, industry knowledge of best practice management and ethical work practices. What is lacking in their view is the monitoring of behaviour and enforcement of policies and expectations required to move equitable practices beyond 'lip service' and a promotional opportunity, to authentic change. Without the threat of consequences, several felt that it was unlikely that employers would genuinely change their behaviour. It was considered particularly challenging to effect behavioural change in decision makers in private practice or at the Bar who were largely self-regulating. 52

Interviewees further stated that the 'only thing these law firms understand is loss of money or loss of reputation', and without a governing body willing to provide some sort of incentive for these firms to care or even comply with initiatives developed by outside professional bodies, then adoption of the Policy would likely be ineffectual. ${ }^{53}$

In 2017, the Victorian Supreme Court released a set of statistics which again displayed the enduring scarcity of speaking roles of women advocates. ${ }^{54}$ It was reported that female barristers only had six per cent of speaking roles in Civil Appeal hearings in the Court of Appeal in 2016 to 2017. ${ }^{55}$ Of barristers who appeared in hearings as juniors during this period, less than 15 per cent were women; a figure far below the actual proportion of women at the Victorian bar, being 29 per cent. ${ }^{56}$ In the Court of Appeal Criminal Division, the percentage of female barristers who had

49 Ibid.

50 Ibid 35,76 .

51 Ibid 39.

52 Ibid 73.

53 Ibid.

54 Victorian Bar, 'Victorian Bar President Calls for Change on Equitable Briefing' (Media Release, 2017); Katie Walsh, 'Women Barely Speak in Victoria's Top Court', Australian Financial Review, 7 September 2017.

55 Ibid.

56 Ibid. 
speaking roles was under 22 per cent, and the percentage of women who appeared was under 23 per cent. 57

Around twenty years ago, the Hunter and McKelvie report identified that both the culture of the Bar and the nature of solicitor briefing practices were causing substantial, widespread disadvantage in the working lives of female barristers. ${ }^{58}$ As seen through the qualitative and quantitative data gathered from 2006 to 2017, it is clear that this remains the case. Such dreary and stagnant statistics also provide further evidence that these discriminatory cultures and practices are heavily institutionalised, and that the various official efforts towards combatting these disadvantages have been mostly ineffective. Therefore, the challenge today lies in devising strategies that are actually capable of making real, foundational change. It should be noted that while briefing policies, which are the primary consideration of this article, are appropriately focused in 'tackling the shortcomings of the solicitors' branch of the profession', 59 they are not, however, adequate in dealing with the culture within the Bar itself, nor do they fully resolve gender prejudice expressed by clients.

\section{The Equitable Briefing Policy}

\section{A A Brief History}

The very first equitable briefing policy seen in Australia was drafted and adopted by the Victorian Bar Council in 2000, and was based very closely on the findings of the Hunter and McKelvie report. ${ }^{60}$ This move was influential across several states, with the Western Australian Bar Association, Western Australian Law Society and the New South Wales Bar Council adopting similar policies in 2003. In light of Hunter and McKelvie's report and the genesis of these state briefing policies, the Law Council of Australia was tasked with developing a national model policy suitable for adoption by the government and private legal profession in 2003.61 On 20 March 2004, a regulatory policy called the Model Equal Opportunity Briefing Policy for Female Barristers and Advocates ('MBP') was formed. ${ }^{62}$ The MBP provides:

In selecting counsel, all reasonable endeavours should be made to:

a) Identify female counsel in the relevant practice area; ... and

b) Genuinely consider engaging such counsel; ... and

Ibid.

Hunter and McKelvie, above n 3; Bartlett, above n 6, 360.

Hunter, above n 30, 36.

60 Victorian Bar Council, Equality of Opportunity Model Briefing Policy (2000); Bartlett, above n 6,361 .

61 The issue was considered at the November 2003 Standing Committee of Attorneys-General Meeting: Bartlett, above n 6, 362.

62 Law Council of Australia, Model Equal Opportunity Briefing Policy for Female Barristers and Advocates (2004). 
c) Regularly monitor and review the engagement of female counsel; $\ldots$ and

d) Periodically report on the nature and rate of engagement of female counsel...63

The MPB has since been amended in 2009 and 2016, and is now named the Equitable Briefing Policy ('EBP'). ${ }^{64}$ The development of the EBP in 2016 was part of a number of initiatives under the Law Council of Australia's Inclusiveness and Diversity Program; a program which was announced in 2015 in response to the NARS Report s findings of the dismal plight of women in the legal profession. ${ }^{65}$

To date, the Australian Bar Association, Australian Capital Territory (ACT) Bar Association, Law Society of Tasmania, and Bar associations and respective law societies of New South Wales (NSW), Northern Territory, South Australia, Victoria, and Western Australia have adopted the Policy. ${ }^{66}$ The Australian Bar Association also called for a number of measures to complement the Policy. The practical steps included the promotion of new readers who come to the bar each year, directives from organisational leadership teams to identify and brief women barristers with relevant expertise and experience, and the practice of silks referring and recommending highly skilled junior women barristers. ${ }^{67}$

Measures of a similar nature and objective have also been implemented by the Bar associations of NSW and Victoria. In late 2016, the NSW Bar Association's Diversity and Equality Committee in conjunction with the Women Barristers' Forum formed an Equitable Briefing Working Group to promote adoption and implementation of the EBP. ${ }^{68}$ The Working Group hosted a variety of seminars and forums which facilitated discussions

63 Ibid.

64 Law Council of Australia, National Model: Gender Equitable Briefing Policy (2016) $<$ http://www.lawcouncil.asn.au/lawcouncil/images/National_Model_Gender_Equitable_Brie fing_Policy_-_June_2016.pdf>.

65 The other notable development in 2016 under the auspices of the Inclusiveness and Diversity Program is the Diversity and Equality Charter, which are a statement of principles that publicly acknowledge a commitment to diversity and equality in the Australian legal profession. The Charter is available for adoption by law societies, bar associations, law firms, chambers, and other entities associated within the legal profession. See Law Council of Australia, IWD 2016 Sees Legal Profession in Unprecedented Push to Improve Inclusiveness and Diversity (Media Release, 8 March 2016); Law Council of Australia, Diversity and Equality Charter (2016) $<\underline{\text { http://www.lawcouncil.asn.au/lawcouncil/images/Diversity and Equality Charter.pdf }>}$

66 For a comprehensive list of the firms and organisations which have adopted the EBP, see Law Council of Australia, National Model Gender Equitable Briefing Policy (2017) $<$ http://www.lawcouncil.asn.au/lawcouncil/lca-divisions?id=499>; Melissa Coade, 'Australian Bar Association Endorses Equitable Briefing', Lawyers Weekly, 31 October 2016.

67 Australian Bar Association, Australian Bar Association Adopts LCA Equitable Briefing Policy and Considers Practical Measures to Implementation (Media Release, 20 October 2016); Melissa Coade, 'Australian Bar Association Endorses Equitable Briefing', Lawyers Weekly, 31 October 2016.

68 Anthony McGrath, 'Gender Equitable Briefing at the Bar' (Gazette, Bar News, Summer 2016). 
across solicitors and barristers on how the EBP may be implemented, and women's experiences in dealing with fellow legal practitioners, the bench, and clients. ${ }^{69}$ In addition to awareness raising initiatives, the Working Group developed a reporting template to assist barristers who elect to adopt the Policy in collecting and detailing the data required for reporting. ${ }^{70}$ The Victorian Bar often collaborates with NSW counterparts in delivering unconscious bias training to members and clerks in an effort to boost diversity. ${ }^{71}$ In addition to being a signatory of the Law Council's EBP, the Victorian Bar is also part of a home-grown program called the Equitable Briefing Initiative. In 2015, the Victorian Bar's Commercial Bar Association developed and implemented this initiative to boost the rate of appearances and pay of women advocates in commercial matters. ${ }^{72}$

The ACT Law Society, Queensland Law Society (QLS), the Bar Association of Queensland, and the Tasmanian Bar are the remaining professional organisations which have not signed onto the Policy. Given that the Policy primarily affects the solicitor branch of the legal profession, it is perplexing as to why it has not been adopted by Bar associations nationwide. The Policy imposes few, if any, duties upon Bar associations, and the refusal to endorse it by the Queensland and Tasmanian Bar may be viewed as an affront to equal opportunity rights. Queensland Law Society's immediate past president, Bill Potts, refused to endorse the Policy on the reasoning that it would impose a 'significant administrative burden' on solicitors. ${ }^{73}$ As an alternative, the QLS launched a networking initiative, the Modern Advocate Lecture Series, to allow 'newly minted barristers to establish rapport and build their profile' ${ }^{74}$ In considering the lengths the Victorian and New South Wales counterparts have gone in accommodating the Policy and increasing representation of women barristers, it is contended that such an effort by the QLS is unsatisfactory. Indeed, lawyers in Queensland have responded to the discord in their own ways, as seen by the establishment of Hemmant's List in late 2016, the state's first clerk-led barristers' list model. ${ }^{75}$ The online list has so far coordinated the briefing of multiple women counsel around Queensland, and was founded to facilitate a more equitable briefing regime in the absence of the Queensland's Law Society and Bar Association endorsement of the EBP. ${ }^{76}$

69 Ibid 28-9.

70 Ibid. See also New South Wales Bar Association, Gender Equitable Briefing Policy: A Guide to Reporting for Barristers (August 2017).

71 Katie Walsh, above n 54.

72 Victorian Bar, Victorian Equitable Briefing Initiative (2016)

$<$ https://www.vicbar.com.au/public/community/equality-diversity-bar/victorian-equitable briefing-initiative>; Victorian Bar, above n 54.

73 Melissa Coade, 'Queensland Walks Own Path on Equitable Briefing', Lawyers Weekly, 13 September 2016.

74 Ibid

75 Melissa Coade, 'Year in Review: The Headlining Acts', Lawyers Weekly, 24 January 2017; See also Hemmant's List, Equitable Briefing $<$ http://hemmantslist.com.au/about/equitablebriefing/>.

76 Ibid. There are currently 42 barristers on Hemmant's list, 20 of which are females. 
To date, there have been no official developments in respect to an alternative briefing policy from the few professional law societies and Bar associations who have not signed onto the EBP.

\section{B The Policy}

The EBP, which launched in late June 2016, directs briefers:

1. To make all reasonable endeavours to brief or select women barristers with relevant seniority and expertise, experience or interest in the relevant practice area;

2. By 1 July 2018:

i. To brief or select senior women barristers account for at least 20 percent of all briefs and/or 20 percent of the value of all brief feeds paid to senior barristers;

ii. To brief or select junior women barristers accounting for at least 30 percent of all briefs and/or 30 percent of the value of all brief fees paid to junior barristers;

Noting the need to adjust these targets to reflect local conditions; and

3. To provide a confidential report...each year with respect to the measures taken to implement these targets. ${ }^{77}$

Compared to its predecessor, there is now a specific, quantifiable target for female advocates to be briefed, and also the requirement to provide a report to the Law Council of Australia or to their local Bar association or law society. The wording has also been altered: in the past, the MBP stated that 'all reasonable endeavours should be made to genuinely consider engaging' female counsel; the EBP now directs briefers 'to make all reasonable endeavours to brief... women barristers.' These amendments are a step in the right direction, importing notions of transparency and accountability in the Policy's application; something which was lacking in its predecessor.

\section{Chief Criticisms of the EBP}

Despite these recent amendments, the EBP's potential in making institutional change continues to be inhibited by the fundamental flaws shared by its predecessor. For instance, the 'Objectives of the Policy' section makes no mention of actually promoting women at the Bar; instead, it prioritises the 'maximisation of choices for legal practitioners and their clients' and 'optimisation of opportunities for practice development of all counsel.' 78 From this, it appears that the EBP focuses more so on procedural fairness and equality of opportunity, and is less concerned with equality of overall result. While the Policy aims for female practitioners to

77 Law Council of Australia, above n 64.

$78 \quad$ Ibid 1. 
be equally considered in briefing, this is by no means an effective method of ensuring the end result of more female practitioners being briefed.

Moreover, the Law Council of Australia explicitly provides that the targets stipulated in the EBP are 'not intended to be quotas' nor are they to 'undermine clients' right to select the barrister(s) to advise and appear on their behalf.' ${ }^{79}$ As seen, the EBP provides no requirement that efforts be made to remove client prejudice. This is a detrimental omission, as there is often no legal or ethical redress for cases where clients clearly express a preference for counsel based on gender. Client preference, in this instance, falls outside the scope of anti-discrimination laws, ${ }^{80}$ and is therefore not an exception to the solicitor's duties in abiding by client instructions. ${ }^{81}$ The primary caveat to this, however, is that if such client prejudice is deemed by the briefing solicitor to be in direct conflict with the best interests of their case; consequently, such instructions may be ignored as an aspect of exercising 'independent forensic judgment' of the solicitor. ${ }^{82}$

Secondly, the targets are not mandatory, and thus remain purely aspirational and recommendatory. Furthermore, the targets are not concrete, and are subject to change if they are 'not achievable due to gender make up in particular areas of practice or geographical locations.' 83 It is conceded that in certain circumstances, there may indeed be a dearth of women available to accept or perform the brief. However, it is critical that such a claim be evidenced by the briefer. Without mechanisms capable in verifying these claims, this exception is susceptible to abuse, with briefing solicitors attributing their failure in briefing female barristers towards an unsubstantiated claim that it was simply impossible to do so, and redirecting the blame onto women barristers.

Where a briefing entity does not meet a target in the EBP, the Law Council of Australia merely states that consideration should be given by that entity as to why it was not achieved. This is hardly an effective mechanism. Not only is there a lack of governing body to enforce a thorough 'consideration', but the fundamental flaw that a briefing entity investigating itself is unlikely to yield any substantive change. This

79 Ibid 5.

80 In Australia, s 5 of the Sex Discrimination Act 1984 (Cth) prescribes that is it unlawful for solicitors themselves to act discriminatory. Similarly, s 22(1) of this Act provides that it is unlawful for those providing 'services' to discriminate against their clients on the grounds of the client's sex. However, there are not reciprocal provisions which apply against the client themselves, or those receiving such services. See also Law Council of Australia, Australian Solicitors Conduct Rules (2015) r 42, which stipulates that a solicitor must not in the course of practice, engage in conduct which constitutes discrimination, sexual harassment, or workplace bullying.

81 See ibid $r$ 7-8.

82 There is some discretion under rules governing solicitors and barristers in most states to exercise independent forensic judgement. See, eg, ibid r 17.1, which provides:

A solicitor representing a client in a manner that is before the court must not act as the mere mouthpiece of the client or of the instructing solicitor (if any) and must exercise the forensic judgments called for during the case independently, after the appropriate consideration of the client's and the instructing solicitor's instructions where applicable.

83 Law Council of Australia, above n 64. 
considerable lack of monitoring of behaviour and enforcement of policies is reiterated in the $N A R S$ Report, inhibiting briefers from moving equitable practices beyond 'lip service' to authentic change. ${ }^{84}$

It has also been documented that the current awareness of the EBP within the private sector is very limited. Firms not only have little understanding of how the Policy operates, but even a lesser idea of how to implement it. ${ }^{85}$ Furthermore, anecdotal evidence has shown that the implementation of the Policy is often driven by the clients, with many specifically requesting that their panel firms identify suitable female counsels for briefing. 86

However, the level of awareness of equitable briefing policies in general appears to be greater within the public sector. In New South Wales, the 2009 Premier's Memorandum requires female Senior Counsel to be identified for any brief to Senior Counsel, and if a woman is not available, an explanation as to why there are no qualified female Senior Counsel. Moreover, the adoption of the EBP by the Commonwealth Department of Public Prosecutions (CDPP) further displays the federal government's endorsement of such cause. ${ }^{87}$

It is acknowledged that the EBP continues to provide valuable beginnings: educating 'briefers' of the availability of female counsel; establishing a process to evaluate whether the policy has resulted in more women being briefed; and prohibiting direct discrimination. Yet, in its current form, the EBP is wholly inadequate in removing client prejudice, lacks discussion regarding the predominance of selection by fraternal networks, and fails to challenge the bases by which counsel are selected; all of which are integral to changing the discriminatory nature of briefing practices between solicitors and the Bar. Coupled with the dismal statistics in relation to gender inequality at the Bar, the current situation provides a rare opportunity to put forth arguments for 'harder' affirmative action policies capable of achieving authentic, foundational change.

\section{Deconstructing the Policy - Merit or Affirmative Action}

\section{A Discursive Framing and Construction of the EBP}

When the MBP was first adopted in 2004 by various Bar associations and law societies, it was made very clear that the policy was "not an affirmative

\footnotetext{
Law Council of Australia, NARS Report, above n 3, 73.

New South Wales Equitable Briefing Group, above n 1, 5.

Ibid.

87 New South Wales Government Premier \& Cabinet, M2009-17 Briefing Senior Counsel (2009). See also Attorney-General's Department, Legal Services Direction (2017) r 4C, which is relevant for the Commonwealth public sector: '4C. All barristers are to be selected for their skills and competency independently of their gender. A Commonwealth agency is to ensure that arbitrary and prejudicial factors do not operate to exclude the engagement of female barristers or to limit the range of barristers being considered for the brief.'
} 
action or quota policy.' 88 The Federal Government expressed a similar sentiment, indicating that the only appropriate regulatory principle for fair briefing was to be founded on 'merit':

The introduction of quotas is not supported. Quotas are regarded as an ineffective tool for achieving progress in this area, mainly because they generate opposition to the policy they are supposed to promote, rather than building support for that policy. Merit should remain the essential criterion for allocating the Commonwealth's legal work and quotas are in conflict with this principle. ${ }^{89}$

These views have not changed over the past decade, meaning that the EBP continues to reflect the same rationales that underlay its predecessor, the MBP. ${ }^{90}$ It is clear that merit is the only legitimate political, philosophical and moral principle for regulation within Australia. ${ }^{91}$ The justification for this is straightforward: for a policy to be based on anything other than merit would lead to the undesirable appointment of 'unqualified' women.

The traditional and conventional understanding of merit is that it is a 'value neutral' selection process capable of finding the best candidate in the most objective and fair manner possible. ${ }^{92}$ Moreover, it is perceived as an apolitical criterion imbued with considerable political and moral significance when it comes to justifying, criticising, or constraining any policy proposals. ${ }^{93} \mathrm{On}$ the other end of the spectrum lies affirmative action, which is understood as 'a range of policies which contemplate the possibility of the selection of a less qualified over a more qualified candidate on the basis of their membership of an under-represented target group.' ${ }^{94}$ Insofar as this narrow definition applies, 'affirmative action' and 'merit' are positioned in a dichotomous relationship with each other, and thus remain inherently in tension.

For this reason, the concept of affirmative action has attracted very little support in Australia and the United Kingdom as a means of promoting diversity in the selection processes of public and professional life..$^{95}$ This has held particularly true in legal contexts such as judicial selection and

88 See, eg, Anthony Howard, Report of Meeting of the Victorian Bar Council Held on 1 April 2004 (2004) 2-3.

89 Legal Services and Native Title Division, Attorney-General's Department, Review of the Legal Services Directions Issues Paper (2004).

90 See, eg, Law Council of Australia, 'Law Council Adopts Equitable Briefing Policy' (Media Release, 24 June 2016); Law Council of Australia, 'Law Council Sets Standards for Equal Opportunity in the Legal Profession' (Press Release, 20 March 2004).

91 Bartlett, above n 6, 365.

92 Ibid. See also Malleson, above n 12, 131. While Malleson's article concerns judicial selection, her analysis of the dichotomous relationship between merit and affirmative action is applicable more broadly.

93 Margaret Thornton, 'Affirmative Action, Merit and the Liberal State' (1985) 2 Australian Journal of Law and Society 28, 29.

94 Bartlett, above n 6, 366; Malleson, above n 12, 127; Thomas Sowell, Affirmative Action Around the World(Yale University Press, 2004) 2.

95 Malleson, above n 12, 127. 
briefing practices, despite the limited success of official efforts going back more than a decade to remedy gender inequality issues within the profession. ${ }^{96}$ There is a prevailing belief that affirmative action policies result in unfairness to individual applicants and a reduction to the overall quality of those selected, making such policies incompatible with meritbased selection systems. This aversion towards affirmative action can be seen in the amendment to the Affirmative Action (Equal Opportunity for Women) Act 1986 (Cth), where it was renamed to the Equal Opportunity for Women in the Workplace Act 1999 (Cth). Thornton describes this amendment as a deletion of all reference to 'forward estimates' or 'objectives' because of the fear of quotas which, as expressed above, results in the appointment of 'unqualified' women without regard to the merit principle. ${ }^{97}$

While the imposition of aspirational targets makes the EBP a considerably more proactive policy than its predecessor, it is still understood as a form of equal opportunity policy rather than hard affirmative action. The intention of such policies is to increase the chances of candidates from under-represented groups to compete equally in the selection process, or for current purposes, the fair competition of briefs; however, they will still ultimately be measured against all other candidates within the pool on the basis of merit. ${ }^{98}$ For this reason, more proactive policies like the EBP are not viewed as undermining the merit principle as they do not reduce the 'quality' of those selected or appointed. The fact that the targets are purely aspirational is fundamental to this vein of reasoning, as such targets will not be met if the only way to achieve them would be to appoint less qualified over more qualified candidates. ${ }^{99}$ It is for this reason that the Law Council of Australia strictly maintains that the targets stipulated in the EBP are purely aspirational, and are not in any way a form of quota. Mandatory quotas, on the other hand, are viewed as a 'practical articulation of fully-blown affirmative action', ${ }^{100}$ and thus a contravention of the merit principle.

However, this article does not subscribe to such understandings of 'merit' and 'affirmative action'. In the following sections, it is argued that merit as a neutral and objective concept capable of finding the best candidate is highly dubious. ${ }^{101}$ It is also argued that affirmative action should be viewed as a much broader and encompassing concept than

96 See above n 3; New South Wales Equitable Briefing Group, above n 1.

97 Margaret Thornton, 'EEO in a Neo-Liberal Climate' (2001) 6 Journal of Interdisciplinary Gender Studies 77, 92. See also Bartlett, above n 6, 366; Barbara Pocock, 'Equal Pay Thirty Years On: The Policy and the Practice' (1999) 32 Australian Economic Review 279, 281.

98 Malleson, above $\mathrm{n} 12,129$. The concept of 'merit' is critiqued later in the article.

99 Ibid

100 Ibid.

101 Carol Bacchi, 'The Brick Wall: Why So Few Women Become Senior Academics' (1993) 18 Oxford Journal of Legal Studies 36, 39, citing Albertine Veldman, “"The Rule of Power": The Implementation of Equal Employment Opportunity Law in a Corporate Setting' (1991) 12 Dutch and Belgian Law and Society Journal 69, 76.; Bartlett, above n 6, 367. 
simply 'the imposition of quotas', and to chiefly reject all affirmative action policies on the basis that they are incompatible with merit-based selection is flawed. To do so limits the range of regulatory options available in formulating an effective policy, as seen in both the MBP and the EBP. As argued by Bacchi: 'Those who advocate substantial structural change need to ensure that they do not buy into conceptual frameworks which undermine their articulated goals... a close study of the concepts employed in reform programmes is a necessary part of the project.' 102

It is conceded, however, that there are a multitude of related arguments against affirmative action, with only one being explicitly 'merit-based'. To that extent, this article should be seen only as a modest contribution to the wider debate for and against affirmative action policies.

\section{B The Merit Principle}

There is a chorus of academics who have criticised merit-based selection on the basis that it is inherently subjective, and often employed to camouflage discriminatory practices. ${ }^{103}$ For instance, Carol Bacchi contends that merit is used to reinforce 'informal cultural values', mask 'contradictory interests, and preserve existing unequal power relations.' 104 Thornton similarly criticises merit as a loose concept that 'permits and legitimates discriminatory practices.' 105 The idea that merit is a neutral and objective concept in selecting the best counsel should be dispensed with. Therefore, for as long as the EBP is underscored by the merit principle, the Policy should be understood as a furtherance of existing briefing practices: simply preserving the institutional status quo that excludes female practitioners from entering and progressing at the Bar, rather than generating any foundational change.

A common approach employed by policy makers towards the concept of merit is the 'maximalist' approach, which assumes 'that, in any situation, the best candidate for the job can be easily identified based on a set of objective criteria.' ${ }^{106}$ However, in processes such as judicial selection or selecting counsel, this is seldom the case. As identified by Hunter and McKelvie, 'selection on merit' in these contexts is rarely attended with an articulated and specific criteria; rather, the criteria will often vary depending on aspects such as the area of law, type of brief, and the client. ${ }^{107}$

102 Carol Bacchi, 'Policy and Discourse: Challenging the Construction of Affirmative Action as Preferential Treatment' (2004) 11 Journal of European Public Policy 128, 144.

103 See, eg, Christopher McCrudden, 'Merit Principles' (1998) 18 Oxford Journal of Legal Studies 543, 543-4. Here, McCrudden argues that the term of 'merit' is so vague that it should not be used at all.

104 Bacchi, above n 101.

105 Margaret Thornton, The Liberal Promise: Anti-Discrimination Legislation in Australia (Oxford University Press, 1994) 19.

106 Malleson, above n 12, 128.

107 Bartlett expands on this point. For instance, in adversarial cases, there may be a natural inclination for a 'desk-thumping' man; or in other circumstances, 'senior' may be synonymous 
Moreover, each briefer will hold different conceptions of the skills and talents required by counsel to perform the brief, and thus favour certain 'criteria' over others as they see fit. ${ }^{108}$ As such, there will rarely be, objectively speaking, only one best candidate for a particular brief; but instead equally as meritorious practitioners that would perform in diverse ways. ${ }^{109}$ There will also never be a clear, neutral, and objective set of selection criteria which can be applied uniformly by briefers due to: changing requirements of the brief itself; the varied and complex functions required of the advocacy profession; and legitimate disagreement amongst briefers on the ranking of relative merits. Therefore, it has been suggested that the "merit principle is often invoked to shroud in mystery the selection processes and thus the criteria used to select counsel.' 110

A particular feature of a strict merit-based system is that the selection criteria must be derived solely on the basis of the functions to be fulfilled. ${ }^{111}$ Critics and supporters of existing selection systems generally agree that in order for the determination of what constitutes merit to be free from prejudice, it must be constructed without taking into account the background of the candidate pool. ${ }^{112}$ However, divorcing the construction of merit from existing candidates is difficult in certain circumstances. An extreme example of this is provided by Malleson, where during the Second World War, the large absence of men left many posts to be filled by women. Consequently, the definition of merit for a wide range of occupations, from manual labourers to senior managers, had to be reconstructed in response to the drastically different disposition of incoming candidates. ${ }^{113}$ Equally, it reverted just as quickly after the war as a means to exclude women and invite the returning male workforce. However, it should be noted that in most instances these women were no less competent in performing the functions of their positions compared to their male counterparts, despite these reconstructions of merit. Nevertheless, it is clear that in certain circumstances, the formulation of merit is heavily interdependent with the candidate pool. This is particularly the case in the area of briefing, reiterating the argument that briefers, when assessing the talents of available counsel, formulate their own conception of how to conduct the case and thus favour certain merits between different candidates. While this is not necessarily objectionable, the understanding that merit is a neutral

with 'male.' The client may also have assumptions about sex, race; alternatively, the client's background may inform selection. See Bartlett, above n 6, 367.

108 Malleson, above n 12, 128; ibid 368.

109 Bartlett, above n 6, 367.

110 Ibid.

111 Malleson, above n 12, 128; Clare Burton, Redefining Merit (1988).

112 The rationale for this view is the recognition that traditional selection processes have constructed merit around the needs of certain preferred groups in a way which has unfairly advantaged them: Malleson, above n 12, 135. See also Department for Constitutional Affairs, Increasing Diversity in the Judiciary, Responses to the DCA Consultation Paper CP 25/04 (2005).

113 Malleson, above n 12, 136. 
and objective concept should be rejected in the context of briefing practices.

In accepting that the candidate pool and the definition of merit are intimately connected, then we must also acknowledge the implication that 'there is no possibility of disengaging the construction of merit from the question of who might be appointed.' 114 Malleson continues:

From this it follows that, in all cases where there is competition for a position, the selection process must formulate the definition of merit through the expression of preferences for certain types of candidates over others. The critical issue therefore becomes the basis on which those preferences are formed. On what basis do selectors determine that certain types of candidate are likely to demonstrate merit? 115

Often the crude answer is that it is those who best mirror the persons already deemed as successfully filling the functions of the position. ${ }^{116}$ Therefore, in the context of briefing, briefs are most commonly awarded to those who simply dominate the cultural capital at the Bar, which are currently male barristers. Moreover, Bartlett writes that those who possess dominant cultural capital, being both male barristers and male briefers, wield 'symbolic mastery by which they can recreate and manipulate briefing culture.'117

The EBP is intended to increase the chances for female practitioners to compete equally in the competition of briefs, but still ultimately be measured against other candidates on the basis of merit. Furthermore, it is premised on the idea that achieving equality of opportunity or procedural fairness in the briefing process will inevitably result in more women receiving briefs. However, as argued above, the process of briefing involves more than being placed on a list and considered; a fundamental aspect is how this consideration is undertaken. The EBP makes a laudable first step in directing briefers to expunge gender and other prejudicial concerns from counsel-selection processes, and prohibiting preference formation based on lack of awareness of any female candidates. The Policy, unfortunately, fails to take the next step, in that it does not provide information on how the briefing process is to be undertaken, or more specifically, what selecting on merit actually means. ${ }^{118}$ This is further complicated by the fact that merit is undefinable in briefing practices due to the countless permutations involving the type of brief, area of law, the client serviced, the candidate pool, and the subjectivity of the briefer itself.

It is conceded that a perfect solution to this may be difficult to formulate. However, the larger point here is to contest the notion that merit-

114 Ibid 137.

115 Ibid.

116 Ibid.

117 Barlett, above n 6, 368.

118 Ibid. Anne Game also provides a similar argument against anti-discrimination policies: Anne Game, 'Affirmative Action: Liberal Rationality or Challenge to Patriarchy?' (1984) Legal Service Bulletin 253. 
based selection is neutral, fair, and objective in selecting the 'best' candidate, and to continue using merit as the underlying rationale of the Policy only serves to be problematic. Moreover, if this alternative analysis is accepted, the social, political, and moral justificatory power of merit is weakened and should no longer be a principle on which to reject affirmative action policies. ${ }^{119}$

\section{Affirmative Action}

It is contended that affirmative action, when properly understood, can refer to many other strategies than simply the imposition of quotas. It is based on a range of rationales and objectives ${ }^{120}$ that provide a plethora of policy options capable of achieving the progression of women at the Bar. To continually confine affirmative action with the reference to quotas obscures the intent of such policies, and thus 'leaves no space for such initiatives to be seriously considered as appropriate responses to an identified area of disadvantage.' 121

Affirmative action is generally understood in other countries in a far more expansive manner, particularly in the United States where it first originated and which holds a long history of implementing such policies. ${ }^{122}$ Indeed, the range of initiatives, policies and programmes which are considered as affirmative action in the United States tend to encompass the mainstream equal opportunities policies which have been in place in the United Kingdom and Australia for the past 40 years. ${ }^{123}$ In its broader context, Malleson writes that:

The term affirmative action can be used to describe any policy or programme directed at addressing the under-representation of members of those groups which have been identified as having been denied equal access to the allocation of education opportunities, employment positions or public office as a result of direct discrimination in the past. ${ }^{124}$

Margaret Thornton similarly expresses it as 'a novel mechanism that is designed to change the profile and culture of a work place in the interests

119 Bartlett, above n 6, 367. See also Malleson, above n 12,138.

120 These may range from rationales of retributive justice, distributive justice, and arguments favouring diversity or social utility: Bartlett, above n 6, 373 .

121 Ibid.

122 There is a plethora of scholarly writing discussing affirmative action laws in the United States: see, eg, Frances Holloway, 'What is Affirmative Action' in Fletcher Blanchard and Faye Crosby (eds), Affirmative Action in Persepctive (1989) 9, 9-19. Epstein, above n 11; Patton, above n 2; Burton, above n 111. Moreover, such policies have been found to be constitutional under the 'equal protection' clause (United States Constitution amend XIV): See, eg, Regents of the University of California v Bakke, 438 US 265 (1978); Schuette v Coalition to Defend Affirmative Action, 572 US 1 (2014). This is also the case in Canada's jurisdiction: Andrews v Law Society of British Columbia [1989] 1 SCR 143.

123 Burton, above n 111.

124 Malleson, above n 12, 127. 
of women and/or designated groups through the initiation of measures at the institutional level.' 125

While both affirmative action and anti-discrimination regulation broadly aim towards promoting equality, the two can be subtly distinguished by the way it is achieved. The former is premised on achieving equality of result, whilst the latter on achieving equality of opportunity or procedural fairness. Faye Crosby and Stacy Blake-Beard provide a useful practical description of the difference between the two:

Affirmative action differs from simple equal opportunity policies in several
ways. First, affirmative action entails the expenditure of effort and resources;
equal opportunity is more passive. Second, affirmative action is planful and
forward looking, requiring organisations to monitor their existing actions and
outcomes and to anticipate future problems, whereas equal opportunity is
reactive, requiring corrective actions only after a problem has been alleged or
discovered. Finally, affirmative action requires that organizations be cognizant
of the ethnic and gender characteristics of people, whereas equal opportunity
does not. Indeed, equal opportunity seeks to encourage a 'colour blind' and
'gender blind' approach.

Much like its predecessor, the EBP falls under both of these definitions. It can be characterised as affirmative action because it proactively targets a specific area of discrimination by briefers for the benefit of female barristers. On the other hand, it is prohibitive in focus, adopting a sameness approach to achieving equality; relying on the presumption that the progression of women practitioners is achieved when given the opportunity to compete in a fair competition for briefs. It does not go further by challenging briefers on the bases by which they select counsel, nor directing briefers to take on broader concerns such as promoting a disadvantaged group; instead, they must simply remain gender blind in their selection processes. It is unfortunate that the EBP continues to shy away from such proactivity. The Policy has the potential to displace gendered briefing practices at the institutional level, but inhibits itself in order to remain an uncontroversial, and therefore unobjectionable policy.

This point is made to display that it is meaningless to define the Policy as either merit or affirmative action, reiterating the need to dispense with the discursive framing that both concepts lie in a dichotomous relationship. Moreover, to perpetuate the aversion that policy makers hold towards anything characteristic of affirmative action limits the range of legitimate regulatory options available in effectively combatting disadvantage at the institutional level.

125 Margaret Thornton, 'Affirmative Action, Merit and Police Recruitment' (2003) 28 Alternative Law Journal 235, 235. See also Thornton, above n 93.

126 Faye Crosby and Stacy Blake-Beard, 'Affirmative Action: Diversity, Merit, and the Benefit of White People' in Michelle Fine et al (eds), Off White: Readings on Power, Privilege and Resistance (2004) 145, 146. 


\section{Rationales of Affirmative Action Policies}

Throughout this article, it has been contended that the merit principle does not provide a strong rationale for the rejection of affirmative action. However, before advocating for 'harder' affirmative action implementations, it is important to at least briefly engage in the debate of using affirmative action as the underlying rationale for any policy.

\section{The 'for' case}

A popular rationale is one based in retributive justice, in which 'preferential treatment' is justified in terms of awarding benefits based on discrimination suffered. This description is intimately connected with moral and political arguments. Wojchiech Sadurksi, in advocating for this rationale, argues that preference should be given to persons singled out on the basis of those very characteristics which have been used in the past to deny them equal treatment. ${ }^{127}$ Another rationale lies in the concept of distributive justice, which describes disadvantaged groups having a right to what they would have gained proportionally in a non-sexist society. ${ }^{128}$ McHarg and Nicolson, from a social utility perspective, argue that affirmative action policies rationalised by distributive justice are 'contributing to some overarching social or organisational goal', such as inclusion and social harmony. ${ }^{129}$ Here, the examples they provide are maternity leave and subsidised childcare, because such initiatives are seen as benefiting society rather than the disadvantaged individual. ${ }^{130}$

One of the more compelling social utility rationales is the promotion of diversity within the legal profession. Hillary Sommerlad argues that allowing excluded, under-represented groups into branches of the legal profession will engender a process of change in the way in which law is practised. ${ }^{131}$ Gilligan similarly contends that the participation of women lawyers will result in 'innovation in and transformation of the practice of law.' ${ }^{132}$ She proposes that the legal profession would see a 'female "ethic of care" which is grounded in a relational, connected, contextual form of reasoning focused on people, as well as the substance of a problem.' ${ }^{133}$

127 Wojcjech Sadurski, 'The Morality of Preferential Treatment (The Competing Jurisprudential and Moral Arguments)' (1984) 14 Melbourne University Law Review 572, 574. See also George Gerapetis, Affirmative Action Policies and Judicial Review Worldwide (Springer International Publishing, 2016).

128 Ronald Fiscus, The Constitutional Logic of Affirmative Action (Duke University Press, 1992).

129 Aileen McHarg and Donald Nicolson, 'Justifying Affirmative Action: Perception and Reality' (2006) 33 Journal of Law and Society 1, 3; Gerapetis, above n 127.

130 Ibid.

131 Hilary Sommerlad, 'Can Women Lawyer Differently? A Perspective from the UK' in Ulrike Shultz and Gisela Shaw (eds), Women in the World's Legal Professions (Hart Publishing, 2003) 192, 194.

132 Carol Gilligan, 'Moral Orientation and Moral Development' in Eva Kittay and Diane Meyers (eds), Women and Moral Theory (Rowman and Littlefield, 1987).

133 Ibid. 
Carrie Menkel-Meadow further argues that this ethic is opposed to 'male moral reasoning' which is 'based on abstracted, universalistic principles applied to problematic situations to create an "ethic of justice".'134 The explicit linkage of gender difference to the ethic of care then leads her to suggest that:

Women lawyers may be more likely to adopt less confrontational, more mediational approaches to dispute resolution...women will be more sensitive to clients' needs and the interests of those who are in relation to each other, for example clients' families or employees...women employ less hierarchical managerial styles... are more likely to have social justice or altruistic motives in practising law... and to develop greater integration between their work and family lives. ${ }^{135}$

The extent of these arguments translating into practice is unknown, nor is it to suggest that women 'lawyer' better than men and vice versa. However, it is clear that there is a wealth of academic literature on the benefits of diversity in the legal profession.

Diversity at the Bar also accords with shared social goals, and that there lies a social good in adopting policies which proactively further female practitioners. For instance, former president of the Law Council of Australia, Tim Bugg, stated that 'the promotion of equal opportunity accords with Australian society's expectations and [is] in furtherance of a legal profession which more truly reflects the diversity of that society and its responsiveness to it.' ${ }^{136}$ Moreover, Bartlett posits that lawyers from previously excluded groups may act as role models and exhibit less of a tendency to perpetuate discriminatory thinking and practices. ${ }^{137}$

\section{The 'against' case}

A chief rationale against affirmative action policies is that it may exacerbate discrimination against the group being provided with assistance. This primarily stems from the belief that merit and affirmative action are positioned in a dichotomous relationship, making affirmative action synonymous with 'preferential treatment' or 'reverse discrimination'. The consequences of this is twofold: firstly, there is the implication that the explicit favouring of women results in discrimination against male barristers; secondly, it may stigmatise all members of the disadvantaged group, being female barristers, as unworthy of the briefs they have received. Barbara Hamilton, in writing on judicial appointment processes, similarly observes that the perception of 'unworthy'

134 Carrie Menkel-Meadow, 'Portia Redux: Another Look at Gender, Feminism, and Legal Ethics' in Stephen Parker and Charles Sampford (eds), Legal Ethics and Legal Practice: Contemporary Issues (Clarendon Press, 1995).

135 Ibid.

136 Law Council of Australia, Model Equal Opportunity Briefing Policy for Female Barristers and Advocates — Implementation Kit: Consultation Draft (2007) 4.

137 Bartlett, above n 6, 379. 
appointment to senior positions potentially increases publicly articulated prejudices. ${ }^{138}$ However, Bartlett writes that this argument appears to 'doom groups subject to discrimination to their fate by the very fact of this prejudice.' 139 While it is conceded that these criticisms may indeed be a difficult reality for women at the Bar, for at least a short period of time, the alternative to continue using uncontroversial yet ineffectual policies is illogical.

The interests of the client also remain a relevant argument against affirmative action policies; particularly those which require the imposition of quotas. Should the client express a preference for counsel based in gender prejudice, solicitor's duties suggest that following client instructions is at least a viable ethical option. ${ }^{140}$ There are also strong incentives for lawyers to cater to clients' preferences - even if it is seeded by gender prejudice - in order to maintain good, working relationships. ${ }^{141}$ It is argued, however, that this is only a problem insofar as the client expresses prejudice. More often than not, clients are entirely guided by their briefing solicitors in relation to counsel selection, ${ }^{142}$ and it is argued that it is in the client's best interest that he or she be advised of the various talents that female barristers present to the case at hand. ${ }^{143}$ There is also nothing prohibiting the briefing solicitor from directly suggesting specific female practitioners to their client. ${ }^{144}$

Drawing from recent times, it appears that the formulation of policies and initiatives is moving towards a more liberal, proactive approach; in other words, there is indication that affirmative action is beginning to become a legitimate political, moral, and social principle for regulation. Malleson argues that as the differentiation between law and politics blurs, the efficiency arguments against 'harder' affirmative action policies to bring about greater diversity become less compelling, and the benefits to be gained from a more diverse legal profession in terms of democratic legitimacy and public confidence grow. ${ }^{145}$ The evidence of this trend is exemplified by Constitutional and Supreme Courts in the United States, South Africa, and Canada, which have seemingly implemented informal quotas in their judicial selection processes. ${ }^{146}$

138 Ibid. See also Barbara Hamilton, "Criteria for Judicial Appointment and "Merit"' (1999) 15 Queensland University of Technology Law Journal 10; Gerapetis, above n 127.

139 Bartlett, above n 6, 381.

140 Client preferences in this instance falls outside the scope of anti-discrimination laws. However, see above $\mathrm{n} 80$ for a more in-depth discussion of this point.

141 It was reported that, in most cases, the will of the client was observed by the solicitor even when this amounted to sheer prejudice on the basis of gender: Hunter and McKelvie, above $\mathrm{n}$ 3, 89-93.

142 Bartlett, above n 6, 371.

143 Ibid 372.

144 Ibid.

145 Malleson, above n 12, 134.

146 Malleson writes that in practice, quotas in different forms, whether formal or informal are widely used in top courts around the world. She argues it would be difficult for any United States President to appoint to the Supreme Court without ensuring that it included at least one women or one black judge. In Canada, where gender equality has a particularly high profile 
While it is conceded that this example of judicial selection is not analogous with briefing practices, there may be some merit given that almost all judges are appointed from the Bar. It is also worth noting that both the NARS Report and the report given by the New South Wales Equitable Briefing Group have expressed the need for some form of target, whether mandatory or not, for the briefing of female counsel. ${ }^{147}$ Perhaps there is mounting impatience towards the pervasive gender inequality issues present within the legal profession, and thus a realisation of the benefits that proactive, affirmative action policies provide in aiding disadvantaged groups.

\section{The Way Ahead}

The following recommendations would be best implemented as amendments to the EBP. It is conceded that the recommendations given below are drastic measures which are sure to be politically divisive, making them difficult to be accepted for implementation. At the very least, they should serve as temporary measures in an effort to create institutional change for women at the Bar.

In combatting client prejudice, there should be a requirement for briefing solicitors to recommend female barristers and to make real efforts to persuade clients not to bring any prejudices to bear. Moreover, we could require the solicitor to advise their clients on the different range of talents that female barristers bring and how these might be useful for the case at hand. This form of 'care' shown to the client may not only assist women to obtain a range of briefs but also be consistent with duties to the client. ${ }^{148}$ This guideline was present in Victoria's version of their briefing policy in 2003, demonstrating support for this kind of recommendation in the past. ${ }^{149}$

It is also recommended that the EBP mandate identification and consideration of female counsel by requiring a list of candidates to be drawn and discussed with the client. This could be implemented by requiring briefing entities to prepare and regularly update an internal referral list or database of female barristers. ${ }^{150}$

and four out of nine Supreme Court Judges, including the Chief Justice, are women, it is doubtful whether there could be fewer than two women on the bench in the future: Ibid.

147 Law Council of Australia, National Attrition and Reengagement Study (NARS): Discussion Paper (2014); New South Wales Equitable Briefing Working Group, above n 1, 9.

148 Bartlett writes that 'care', in the context of legal ethics, pertains to the appropriate relationship between lawyer and client. This relationship not only encompasses duties of loyalty and zealousness to the client's best interest, but also the discretion to consider a variety of other considerations that may affect the client or others involved in the case: Bartlett, above n 6 , 372. See also Rhode, above n 28.

149 Ibid.

150 Women Lawyers Association of Queensland (WLAQ) recently compiled the 'female barristers list', documenting all female barristers at the private bar in Queensland in order of seniority, and listed under their respective areas of practice: Women Lawyers Association of Queensland, Female Barristers List (2017) < content/uploads/2016/12/Female-Barristers-List-v4.0.pdf $>$. 
The EBP should be also amended to direct intra-firm policies and reviews each year to ensure practical, rather than symbolic compliance. Intra-firm policies should include education and awareness-raising initiatives, in which firms and briefers are made aware of the sexist culture at the Bar, current gendered briefing practices, and the benefits that gender equality and diversity bring to the profession. Completion of such programs should count towards Continuing Professional Development (CPD) units which are required by practitioners each year to maintain their practising certificate. This vein of thinking has recently come to fruition, where in March 2017, diversity and inclusion specialists, Symmetra, developed CPD accredited workshops addressing unconscious bias within the legal profession. ${ }^{151}$ This unprecedented program offered to lawyers and legal practices include an interactive exploration of unconscious cognitive biases, how they affect decision making, and ways to identify and counteract such biases. Law Council of Australia President, Fiona McLeod $\mathrm{SC}$, has expressed strong support for this initiative, stating that the training was a clear indication of the profession taking practical steps towards greater inclusion and diversity. ${ }^{152}$

The imposition of mandatory quotas should be considered insofar as it does not conflict with client preference. Furthermore, briefers should be required to provide a publicly available report to their respective law society or Bar association, as opposed to merely a confidential one. ${ }^{153}$ The report should provide an explanation of why apparently eligible women were overlooked in the awarding of a brief. Hopefully this will provide a more thorough response than 'female barristers were simply not meritorious enough.' 154 A failure to meet such targets, either mandatory or not, should also be met with some form of punishment in order to move equitable briefing practices beyond 'lip service' to authentic change. ${ }^{155}$ An appropriate authority to oversee this would be the Legal Services Commission in respective states and territories.

Another recommendation is the requirement for briefers, law societies, and Bar associations to provide quantitative and qualitative information in relation to the briefing of female barristers to media agencies. The rationale being to educate the public and also, perhaps, publicly shame those who continue to exhibit gendered briefing practices. This media strategy stems from several newspaper articles which reported upon the severe gender disparity of partners in law firms. ${ }^{156}$ This will hopefully foster movement on the demand side of briefing, in which clients will not only be more aware of gender inequality at the Bar, but also specifically ask for

151 Law Council of Australia, 'Unconscious Bias Training Now Available to all Australian Lawyers', above n 41.

152 Ibid.

153 Obviously, this should only go so far in that it does not breach client confidentiality.

154 New South Wales Equitable Briefing Group, above n 1, 8.

155 Ibid 4

156 See, eg, Edmund Tadros, 'One in Three New Legal Partners Are Women', Australian Financial Review, 30 June 2016; Chris Merritt, 'Firms Push Ahead with Female Equity Partnerships', The Australian, 1 July 2016. 
representation by a female barrister. This will also help remedy the problem regarding limited awareness and understanding of the Policy in private firms and the general public.

\section{Conclusion}

This article has attempted to display the pervasive and enduring nature of gendered briefing practices at the Bar, and how they contribute to the widespread disadvantage that female practitioners face in their working lives. Moreover, it has analysed the regulatory responses by the Law Council of Australia - specifically the EBP's effectiveness, criticisms, and how it has been constructed in the context of merit versus affirmative action. By analysing the concept of merit and affirmative action, it is suggested that placing the two concepts against each other, in a dichotomous relationship, is flawed, and only serves to inhibit effective policy making. It is concomitantly argued that privileging merit, particularly in the context of briefing practices, is contentious. In developing a regulatory response to female disadvantage at the Bar, it is important that a range of options are considered. Drawing from the analysis above, it is contended that future briefing policies must implement mandatory, proactive, and specific measures in order to promote change at an institutional level. 